\title{
Fabrication and Characterization of an Asymmetric Polyurethane Membrane for Use as a Wound Dressing
}

\author{
W. L. J. Hinrichs, E. J.C. M.P. Lommen, ${ }^{\star}$ Ch. R. H. Wildevuur, ${ }^{\star}$ and J. Feijen \\ Department of Chemical Technology, University of Twente, 7500 AE Enschede, The Netherlands; *Department of \\ Cardiopulmonary Surgery, Research Division, University Hospital of Groningen, 9700 RB Groningen, The Netherlands
}

\begin{abstract}
To prevent wound dehydration and bacterial penetration, a wound dressing should be occlusive, but on the other hand it should also be permeable for wound exudate to prevent bullae formation. To meet these requirements a new type of polyurethane wound dressing which consists of a microporous top layer (pore size $<0.7 \mu \mathrm{m}$ ) supported by a sublayer with a highly porous sponge-like structure containing micropores (pore size $<10 \mu \mathrm{m}$ ) as well as macropores (pore size: $50-100 \mu \mathrm{m}$ ) was designed. The pores of both layers are interconnected and form a continuous structure in the membrane. Membranes according to this design were prepared either by means of a two-step or by means of a one-step casting process. Both fabrication methods are based on phase inversion techniques. Asymmetric polyurethane Biomer ${ }^{(3)}$ membranes prepared by the two-step casting process were tested in vivo as full thickness skin substitutes using guinea pigs. Neither wound dehydration nor infections were observed while the drainage capacity of the wound dressing was effective in preventing bullae formation. Furthermore the wound dressing remained firmly adhered to the wound surface during the whole process of wound healing. In contrast to all other commercial wound dressings currently available the polyurethane wound dressing applied on excised clean wounds did not need to be replaced during healing but could be left on the wound until full regeneration of the skin had taken place after which it was spontaneously repelled. () 1992 John Wiley \& Sons, Inc.
\end{abstract}

\section{INTRODUCTION}

To protect a skin defect from infections and dehydration, the wound has to be protected from its environment. Protection can be accomplished by covering the wound with wound dressings which have occlusive characteristics like Opsite ${ }^{\circledR},{ }^{1,2}$ Omiderm ${ }^{\circledR 1,3}$ or Spandre ${ }^{\circledR}$. ${ }^{1}$ Because these wound dressings are relatively impermeable for water, wound exudate beneath the dressing can easily accumulate which results in tissue maceration, bullae formation, infections, and finally detachment of the dressing from the wound surface. Ideally, the passage of fluids through the dressing should be balanced with the production of wound exudate. With the wound dressings mentioned, the transport of fluids is restricted to evaporation of water through the material which is generally a slow process. Despite many efforts to develop wound dressings with an increased water vapor permeability, the drainage capacity in most cases is not sufficient to prevent the formation of blisters. To drain the accumulated fluids, dressings have to be replaced or have to be punctured. Some dressings like

Requests for reprints should be sent to Prof. Dr. J. Feijen, Department of Chemical Technology, University of Twente, P.O. Box 217, 7500 AE Enschede, The Netherlands.

Journal of Applied Biomaterials, Vol. 3, 287-303 (1992)

(C) 1992 John Wiley \& Sons, Inc.

CCC $1045-4861 / 92 / 040287-17$
Biobrane ${ }^{\circledR}$ are already provided with pinholes. However in this case the protection against microbial invasion is lost. ${ }^{1,4-8}$

Standard cotton or paraffin gauzes but also highly sophisticated wound dressings like Coldex ${ }^{\circledR 1}$ and Surfasoft ${ }^{\circledR 1}$ are based on macroporous structures. Due to the high absorption capacity of these dressings, an effective drainage of wound exudate is achieved. However the open structure also allows bacteria to pass the dressing which may result in wound infections. Furthermore the evaporative water loss is not sufficiently reduced which may lead to wound dehydration. Another drawback is that these dressings have to be replaced regularly thereby increasing the risks of wound infection and disturbing wound healing.

Lyofoam $^{\circledR},{ }^{1,8}$ Epigard $^{\circledR},{ }^{1,8-10}$ and Duoderm ${ }^{\circledR}, 1$ are examples of water absorbing wound dressings whereby the design principles of the two types of dressings mentioned are combined. These dressings consist of a macroporous sublayer or a hydrogel which is linked to a dense or hydrophobic microporous top layer. At the initial stages of application, the absorbing layer efficiently depletes the wound from superfluous exudate. However since the top layer does not allow the passage of fluids, the drainage capacity is limited. As soon as the absorbing layer is saturated, exudate accumulates beneath the dressing or leaks at the edges. Therefore also this type of dressing needs frequent replacement again increasing the risks of wound infection. 
It can be concluded that the wound dressings currently available do not meet the concomitant requirements of being sufficiently occlusive to prevent bacterial penetration and rapid wound dehydration and sufficiently permeable to prevent blister formation.

In this article we present a new design for a wound dressing which does meet both requirements. The wound dressing consists of an asymmetric polyurethane membrane. The top layer which contains interconnected micropores is designed to prevent bacterial penetration and rapid dehydration of the wound surfaces but allows the passage of wound exudate. The top layer is supported by a sublayer which has a macroporous sponge-like structure. The sublayer is designed to achieve a high absorption capacity for fluids, drainage of the wound by capillary forces, and to establish a firm adherence of the wound dressing to the wound surface.

The wound dressing according to this design was prepared either by means of a two-step or by means of a one-step casting process. Both fabrication methods and the physical characteristics of the wound dressing will be presented. Furthermore the results of the treatment of full thickness skin defects on guinea pigs with the wound dressing made by means of the two-step casting process will be discussed.

Biobrane $^{\circledR}$, a commercially available wound dressing, was used as a reference material. This wound dressing consists of a perforated silicon rubber top layer which is mechanically bonded to a knitted nylon mesh.

\section{METHODS AND MATERIALS}

\begin{abstract}
Materials
Polyetherurethane urea Biomer ${ }^{\circledR}$ (PEUU), polyetherurethane Pellethane ${ }^{\circledR} 2363$ 80AE (PEU), and polyvinylpyrrolidone k90 (PVP, molecular weight 360.000) were purchased from Ethicon, Norderstedt, West Germany, Dow Chemical, Terneuzen, The Netherlands, and Janssen Chimica, Tilburg, The Netherlands, respectively. The polymers were used without further purification. Solvents and nonsolvents $\mathrm{N}, \mathrm{N}$-dimethylacetamide (DMAC), $\mathrm{N}$-methyl-2pyrrolidone (NMP), ethanol, and methanol (all Merck, Darmstadt, West Germany) were of synthesis grade. $\mathrm{I}_{2}$, $\mathrm{KI}, \mathrm{ZnSO}_{4} \cdot \mathrm{H}_{2} \mathrm{O}$, and acetic acid (all Merck, Darmstadt, West Germany) were of analytical grade. Sodium citrate (Janssen Chimica, Tilburg, The Netherlands) was recrystallized from a methanol/water mixture and fractionated on particle size using Tamson test sieves with mesh sizes of 63 and $106 \mu \mathrm{m}$ (Tamson, Zoetermeer, The Netherlands). Nonwoven polypropylene Freudenberg 2406 was obtained from Freudenberg, Weinheim, West Germany.
\end{abstract}

\section{Preparation of the Wound Dressing by Means of the Two-Step Process}

The wound dressing was prepared by means of a two-step casting process according to a technique developed by
Gogolewski et al. ${ }^{11,12}$ and modified for our applications. First the sublayer was prepared. Sodium citrate $(80 \mathrm{~g})$ with a particle size of 63 to $106 \mu \mathrm{m}$ was added to a solution of Biomer in DMAC $(100 \mathrm{~g}, 7.9 \mathrm{wt} \%)$. The resulting suspension was heated to $50{ }^{\circ} \mathrm{C}$ under vigorous stirring and degassed. The suspension was cast onto a glass plate using a Doctor blade to obtain a film with a thickness of $350 \mu \mathrm{m}$. The film was immersed into an ethanol/water mixture $(5 / 1(\mathrm{w} / \mathrm{w}))$ at ambient temperature. After $2 \mathrm{~min}$ of coagulation, the film was exposed to air until nearly dry. The top layer was prepared using a degassed solution of Biomer ${ }^{\circledR}$ in DMAC $(10.3 \mathrm{wt} \%)$ heated to $50{ }^{\circ} \mathrm{C}$. A layer of this solution was applied on top of the first layer using a Doctor blade adjusted to a casting height of $350 \mu \mathrm{m}$. The layered structure was then transferred into ethanol at ambient temperature during $10 \mathrm{~min}$ and subsequently into water also at ambient temperature. After complete precipitation of the polymer, the membrane was thoroughly rinsed with water and ethanol to remove the salt particles and solvent residues. Subsequently, the product was dried and sterilized by ethylene oxide.

\section{Preparation of the Wound Dressing by Means of the One-Step Procedure}

Polyurethane membranes were prepared either by immersion precipitation or by phase inversion from the vapor phase followed by immersion precipitation using a casting machine as shown in Figure 1.

Initial experiments, using NMP as a solvent and water as a nonsolvent for the polyurethane, showed that smooth carrier materials could not be used in this system.

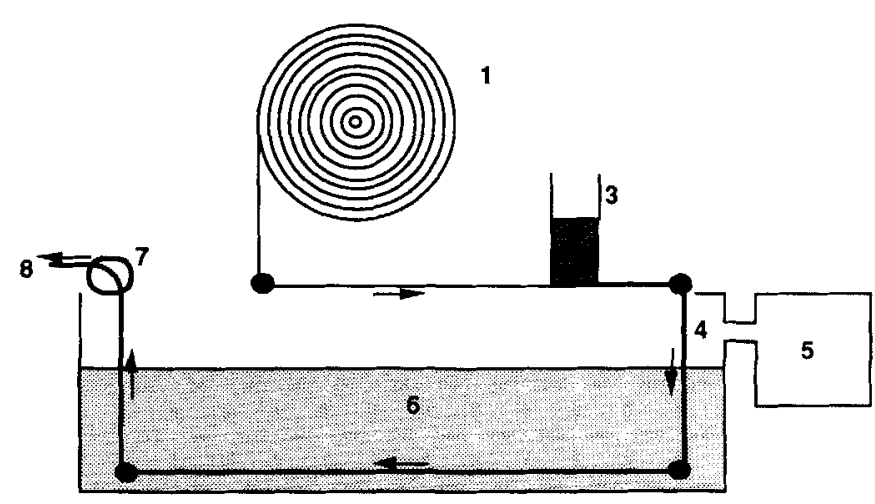

Figure 1. Schematic drawing of the casting machine. With the casting machine, a carrier (1) is transported with an adjustable rate through a coagulation bath using a transport device (7). Before entering the coagulation bath a layer of a polymer solution (2) with an adjustable thickness is cast on a carrier using a Doctor blade (3). This solution can be exposed to nonsolvent vapor (4) using the vapor generator (5) before the polymer film is immersed into the coagulation bath (6). The residence time of the polymer film in the vapor gap can be regulated with the transport device. The vapor is kept saturated with water using the vapor generator. The water concentration in the vapor gap can be varied by changing the temperature. After precipitation of the polymer in the coagulation bath, the membrane is transported into a rinsing bath (8) to remove solvent residues. Subsequently the membrane is removed from the carrier, dried, and used for further experiments. 
Due to extensive shrinkage of the polymer film during coagulation, the membrane detached from the carrier and rumpled. After testing different carrier materials, it appeared that the adherence of the polymer film to roughened surfaces was sufficient to allow relaxation of the polymer thus preventing shrinkage. To prevent distuption of the membrane during the removal of the membrane from the carrier, the adherence should not be too strong. It was found that microporous nonwoven polypropylene fabric Freudenberg 2406 does meet the desired properties. Therefore this carrier material was used in further experiments. Membranes were prepared using the process conditions as listed in Table I.

\section{PVP Content of the Membranes}

Solutions of PEU and PVP in NMP [PEU/PVP/NMP = 10/5/85 (wt \%)] or PEU and PVP in NMP and ethanol $[\mathrm{PEU} / \mathrm{PVP} / \mathrm{NMP} / \mathrm{ethanol}=10 / 5 / 60 / 25(\mathrm{wt} \%)]$ were cast on a nonwoven and subsequently immersed into a water bath. The ratio of the amounts of the polymer solution and the water in the water bath was chosen in such a way that the final PVP concentration in the water bath would become 40 to $80 \mathrm{ppm}$ if all PVP would be extracted from the membrane into the water bath. The PVP concentration in the water bath was determined colorimetrically. Therefore $2 \mathrm{~mL}$ acetic acid and $5 \mathrm{~mL}$ iodine reagent $\left(2.5 \cdot 10^{-3} \mathrm{M} \mathrm{I}_{2}+1.3 \cdot 10^{-2} M \mathrm{KI}\right.$ in $2.5 \mathrm{wt} \%$ solution of $\mathrm{ZnSO}_{4}$ in water) were added to samples of $8 \mathrm{~mL}$. The extinction of the resulting mixture was measured at $432 \mathrm{~nm} .{ }^{13,14}$ The concentration of PVP was obtained using a calibration curve. Control experiments showed that the presence of ethanol and NMP in the water bath had no influence on the extinction values obtained.

First it was investigated in which way the variation of the concentration of PVP in the water bath in time is governed by adsorption or absorption or by desorption of PVP from the membrane and whether the extraction medium meets sink conditions. Therefore solutions of composition PEU/PVP/NMP/ethanol $=10 / 5 / 60 / 25(\mathrm{wt} \%)$ were cast on a nonwoven and immersed in a water bath. During a 2-week period the water was replaced three times and the total amount of PVP released was determined. In a second experiment the same procedure was performed except that the water was not replaced. It was found that exchanging the water did not have an effect on the total amount of PVP released from the membrane. In another series of experiments solutions of composition PEU/NMP/ethanol $=15 / 60 / 25(\mathrm{wt} \%)$ were cast on a nonwoven and immersed in solutions of PVP in water with concentrations of either 20,50 , or $80 \mathrm{ppm}$. In these cases the PVP concentration in the water bath did not decrease in time. These experiments indicate that under the experimental conditions used no adsorption or absorption of PVP from the water bath onto the membrane occurred and that the water bath does meet sink conditions.
In preliminary experiments it was found that after 1 to 2 weeks the PVP concentration in the extraction medium became constant (an example of the kinetics of a leaching experiment is shown in Fig. 2). Therefore incubation times of 2 weeks were used to determine the residual amounts of PVP in the membranes (see Table II).

In some experiments ethanol instead of water was used as extraction medium. To determine the amount of extracted PVP, the ethanol was evaporated and the precipitated PVP was redissolved in water. The PVP concentration in the resulting aqueous solution was determined as described above.

\section{Microstructure}

To investigate the pore structure of the membranes, samples were goldsputtered and examined with a Jeol JSM-35CF scanning electron microscope. Bubblepoint measurements using a Coulter Porometer and Porofil ${ }^{\circledR}$ as a wetting agent were carried out to determine the maximum pore size in the top layer of the membranes.

\section{Mechanical Properties}

Force-strain measurements of the wound dressing prepared by means of the two-step or the one-step casting process (Table I, Experiment 17) were performed using an Instron tensile tester. Samples with a width and length of $10 \mathrm{~mm}$ were tested with a strain rate of $5 \mathrm{~mm} / \mathrm{min}$ until breakage.

\section{Drainage Capacity}

The permeability of the wound dressing for fluids was measured as follows. A hollow tube with a diameter of $2 \mathrm{~cm}$ was sealed at one end with the wound dressing prepared by means of the two-step or the one-step casting process (Table I, Experiment 17), or with Biobrane ${ }^{\circledR}$ and then filled with serum. Subsequently the flow of serum passing through the membrane was measured. The height of the column was varied between 1 and $12 \mathrm{~cm}$. During each measurement, the height of the column was kept constant by adding serum. ${ }^{15}$ The specific drainage capacity was calculated using the formula $D=Q / P A$, where $Q$ is the flow, $P$ is the hydrostatic pressure (height of the column in $\mathrm{cm}$ serum), and $A$ is the surface area of the membrane.

\section{Bacteriology}

Circular discs with a diameter of $1.5 \mathrm{~cm}$ were cut from the wound dressing prepared by means of the two-step casting procedure $(n=30)$ and from Biobrane ${ }^{\circledR}(n=30)$. The samples were sterilized with ethylene oxide and placed on agar plates. Subsequently the center of each disc was inoculated with a suspension $(0.2 \mathrm{~mL})$ of an overnight culture of pseudomonas aeruginosa $\left(10^{8}-10^{9}\right.$ bacteria $\left./ \mathrm{mL}\right)$. After $24 \mathrm{~h}$ of incubation at $37{ }^{\circ} \mathrm{C}$ the agar plates were checked for bacterial contamination by means of standard techniques. ${ }^{15}$ 
TABLE I. Process Conditions Used for the Preparation of the PEU Membranes with the Casting Machine

\begin{tabular}{|c|c|c|c|c|c|c|}
\hline \multirow[b]{2}{*}{ Exp. } & \multicolumn{4}{|c|}{ Composition Casting Solution (wt\%) } & \multirow{2}{*}{$\begin{array}{c}\text { Temp. Vapor } \\
\left({ }^{\circ} \mathrm{C}\right)\end{array}$} & \multirow{2}{*}{$\begin{array}{l}\text { Residence Time in the } \\
\text { Vapor Gap (s) }\end{array}$} \\
\hline & PEU & PVP & NMP & Ethanol & & \\
\hline 1 & 10 & - & 90 & - & - & 1.8 \\
\hline 2 & 15 & - & 85 & - & - & 1.8 \\
\hline 3 & 10 & 5 & 85 & - & - & 1.8 \\
\hline 4 & 10 & - & 65 & 25 & - & 1.8 \\
\hline 5 & 10 & 5 & 60 & 25 & - & 1.8 \\
\hline 6 & 10 & - & 90 & - & 70 & 1.8 \\
\hline 7 & 15 & - & 85 & - & 70 & 1.8 \\
\hline 8 & 10 & 5 & 85 & - & 70 & 1.8 \\
\hline 9 & 10 & 一 & 65 & 25 & 70 & 1.8 \\
\hline 10 & 10 & 5 & 60 & 25 & 70 & 1.8 \\
\hline 11 & 10 & 5 & 60 & 25 & 70 & 32.5 \\
\hline 12 & 10 & 5 & 60 & 25 & 70 & 12.4 \\
\hline 13 & 10 & 5 & 60 & 25 & 70 & 8.8 \\
\hline 14 & 10 & 5 & 60 & 25 & 70 & 6.5 \\
\hline 15 & 10 & 5 & 60 & 25 & 70 & 5.1 \\
\hline 16 & 10 & 5 & 60 & 25 & 70 & 2.4 \\
\hline 17 & 10 & 5 & 60 & 25 & 70 & 1.8 \\
\hline 18 & 10 & 5 & 60 & 25 & 70 & 1.4 \\
\hline 19 & 10 & 5 & 60 & 25 & 45 & 1.8 \\
\hline 20 & 10 & 5 & 60 & 25 & 55 & 1.8 \\
\hline 21 & 10 & 5 & 60 & 25 & 65 & 1.8 \\
\hline 22 & 10 & 5 & 60 & 25 & 70 & 1.8 \\
\hline 23 & 10 & 5 & 60 & 25 & 80 & 1.8 \\
\hline 24 & 10 & 5 & 60 & 25 & 85 & 1.8 \\
\hline
\end{tabular}

In all experiments a layer of the polymer solution was cast on a microporous nonwoven polypropylene fabric Freudenberg 2406 with a Doctor blade which was adjusted at a casting height of $400 \mu \mathrm{m}$. Water of $48^{\circ} \mathrm{C}$ was used as coagulation bath.

\section{In vivo Experiments}

Adult male guinea pigs weighing 600 to $700 \mathrm{~g}$ were used as experimental animals. After being anaesthetized with Fluothane ${ }^{\circledR}$ and a $\mathrm{N}_{2} \mathrm{O} / \mathrm{O}_{2}$ gas mixture $(2 / 1)$ their backs were shaved with electric clippers and desinfected using

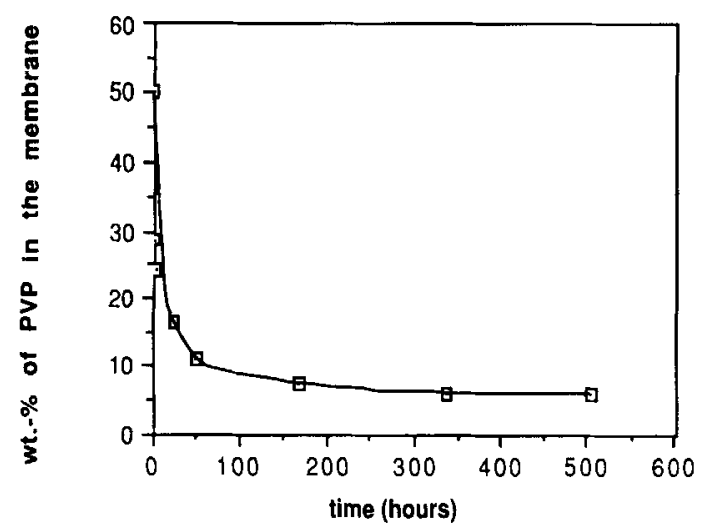

Figure 2. Concentration of PVP in the membrane versus the extraction time. The membrane was prepared by casting a solution of composition PEU/PVP/NMP/ethanol $=10 / 5 / 60 / 25$ (wt $\%$ ) on a nonwoven which was subsequently immersed into a water bath at $48{ }^{\circ} \mathrm{C}$. povidone iodine. Under sterile conditions, a $6 \times 8 \mathrm{~cm}$ full thickness skin excision up to the panniculus carnosus was created under sterile conditions. Subsequently the skin defect was treated with the polyurethane wound dressing prepared by means of the two-step casting process $(n=8)$ or with Biobrane ${ }^{\circledR}(n=8)$. Wound drainage was evaluated by visual wound inspection.

In a second series of experiments would healing was evaluated histologically. Therefore the skin defects were treated with the polyurethane wound dressing prepared by means of the two-step casting process $(n=8)$. Biopsies were taken weekly during the entire time of wound healing (7 weeks) and prepared for light microscopy (LM) using standard techniques. ${ }^{15}$

In an additional series of experiments, the adhesion of the wound dressing to the wound surface was evaluated. Therefore circular full thickness skin excisions (diameter $2 \mathrm{~cm}$ ) created on the backs of guinea pigs were covered with the polyurethane wound dressing prepared by means of the two-step casting process $(n=2)$. After $5 \mathrm{~h}$, the wound dressing and underlying tissue was frozen by ethylchloride spraying and then carefully excized. Subsequently the samples were immersed into liquid nitrogen 
TABLE II. PVP Extraction Experiments ${ }^{a}$

\begin{tabular}{|c|c|c|c|c|c|c|c|c|c|}
\hline \multirow{2}{*}{\multicolumn{4}{|c|}{$\begin{array}{l}\text { Composition Casting } \\
\text { Solution (wt } \% \text { ) }\end{array}$}} & \multicolumn{6}{|c|}{ Extraction Conditions ${ }^{b}$} \\
\hline & & & & \multicolumn{3}{|c|}{ A } & \multicolumn{3}{|c|}{ B } \\
\hline PEU & PVP & NMP & Ethanol & $\begin{array}{c}\text { Time } \\
\text { (weeks) }\end{array}$ & $\begin{array}{l}\text { Temp } \\
\left({ }^{\circ} \mathrm{C}\right)\end{array}$ & Medium & $\begin{array}{l}\text { Time } \\
\text { (weeks) }\end{array}$ & $\begin{array}{l}\text { Temp } \\
\left({ }^{\circ} \mathrm{C}\right)\end{array}$ & Medium \\
\hline 10 & 5 & 85 & - & 2 & 20 & water & - & - & - \\
\hline 10 & 5 & 60 & 25 & 2 & 20 & water & - & 一 & - \\
\hline 10 & 5 & 60 & 25 & 2 & 48 & water & - & - & - \\
\hline 10 & 5 & 60 & 25 & 2 & 20 & water & 2 & 48 & water \\
\hline 10 & 5 & 60 & 25 & 2 & 48 & water & 2 & 48 & ethanol \\
\hline
\end{tabular}

${ }^{a}$ Experiments were carried out in fivefold.

${ }^{b}$ Extraction procedure $\mathrm{A}$ was followed by extraction procedure $\mathbf{B}$.

after which the wound dressing was pulled loose from the tissue. The tissue was then fixed with glutaraldehyde and prepared for SEM using standard techniques. ${ }^{15}$

\section{RESULTS AND DISCUSSION}

\section{Preparation of the Wound Dressing by Means of the Two-Step Procedure}

Besides the requirements mentioned in the introduction, a wound dressing should be flexible and sufficiently elastic to conform to body movements and contours. Furthermore the material should exhibit a good processability, biocompatibility, should be sterilizable, and may not degrade within the time of application. We have selected the polyetherurethane urea Biomer ${ }^{(3)}$ for the preparation of the wound dressing because this material has already been applied clinically for several implantation purposes and meets the requirements listed above. ${ }^{16-19}$

The wound dressing according to our design could be prepared via a two-step procedure using immersion precipitation techniques (Figs. $3 a-c)$. With this procedure membranes composed of two distinct layers are obtained. The sublayer with a thickness of $100 \mu \mathrm{m}$ has a highly interconnected fibrillar sponge-like structure in which macropores with a size of 50 to $100 \mu \mathrm{m}$ and micropores with a size smaller than $5 \mu \mathrm{m}$ can be distinguished. The top layer with a thickness of 10 to $20 \mu \mathrm{m}$ contains only micropores. These pores, which have a size smaller than $0.7 \mu \mathrm{m}$ at the surface of the membrane, are also interconnected and form a continuum with the pores of the sublayer.

The two types of pores in the sublayer are formed by two different mechanisms. After immersion of a suspension of a polymer solution and sodium citrate particles in an ethanol/water mixture the polymer precipitates and the salt particles are encapsulated by the precipitated polymer. At a later stage of the preparation the membrane is immersed in a water bath. The entrapped salt particles dissolve resulting in the formation of macropores. The size and density of these pores are determined by the size of the salt particles and the salt/polymer ratio used. The micropores are formed as a result of demixing processes during the immersion of the suspension in the ethanol/water bath. The exchange of the solvent by the nonsolvent induces phase separation into polymer-rich and polymer-poor domains. The polymer matrix is obtained after solidification of the polymer-rich domains whereas the pores originate from the polymer-poor domains. The size and the density of these pores are determined by the type of polymer, solvent and nonsolvent used, as well as by the process conditions applied such as polymer concentration and temperature. A polymer solution without sodium citrate particles was used to prepare the top layer. Therefore this layer only contains micropores.

The sublayer can be firmly linked to the top layer by the following procedure. The sublayer is prepared by placing the polymer solution containing salt particles into the ethanol/water bath for only $2 \mathrm{~min}$. As a consequence not all DMAC will diffuse into the coagulation bath and a certain amount of solvent will be left in the membrane. Because DMAC has a low volatility as compared to ethanol/water, the solvent contents of the membrane will be hardly reduced during the drying step. Therefore casting of a second layer on top of the sublayer will result in redissolution of some of the polymer of the sublayer near the boundary of the two layers before the coagulation of the polymer in the ethanol bath starts. In this way an adequate fusion of the sub- and top layer of the membrane is achieved.

\section{Preparation of the Wound Dressing by Means of the One-Step Procedure}

Fabrication of the wound dressing by means of a twostep procedure has some disadvantages. The fabrication procedures are rather laborious and difficult to perform. To prepare the sublayer large amounts of salt particles are needed. Furthermore the wound dressing is hand made and a continuous process is preferred. Finally with regard to safety and the generation of toxic waste products the use of DMAC as a solvent and ethanol as a nonsolvent has to be avoided when possible.

Therefore the possibilities to prepare a polyurethane membrane with the desired pore structure by means of a 
continuous process were investigated. The less toxic NMP was used as a solvent instead of DMAC and water was used as a nonsolvent while no sodium citrate particles were applied. Furthermore Pellethane $\left.{ }^{(}\right) 2363$ 80AE was used instead of Biomer ${ }^{\circledR}$. We have selected this particular polymer for its relatively low cost and because it does also meet the prerequisites as a material for the wound dressing according to our design. . $^{17,19,20}$

Polyurethane membranes were prepared from polymer solutions with different compositions either by immersion precipitation or by phase inversion from the vapor phase followed by immersion precipitation (see Table I).

In the first series of experiments the solutions were cast and subsequently immersed into the water bath without applying the vapor generator. In these experiments membranes with asymmetric pore structures were obtained. The membranes consisted of a dense top layer supported by a macroporous sublayer. This type of pore structure is usually found when polymer solutions are immersed into a pure nonsolvent. ${ }^{21-25}$ It has been shown in several

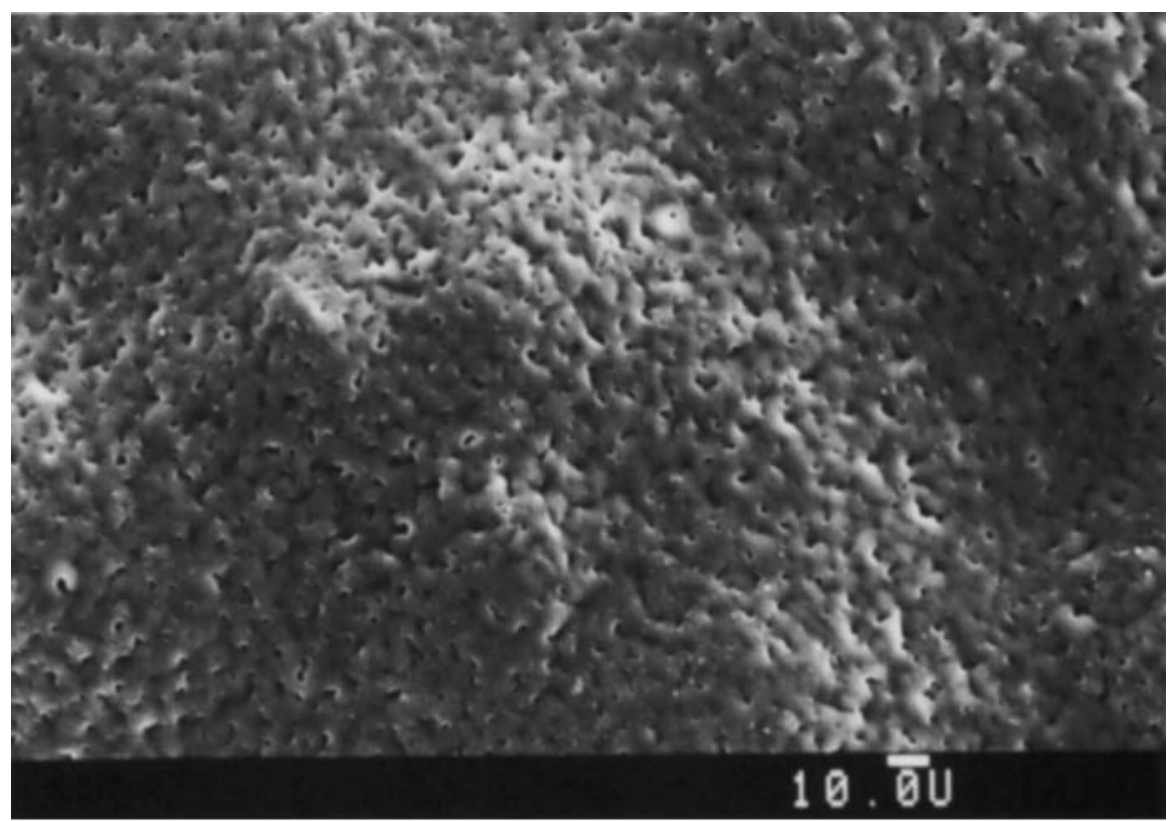

(a)

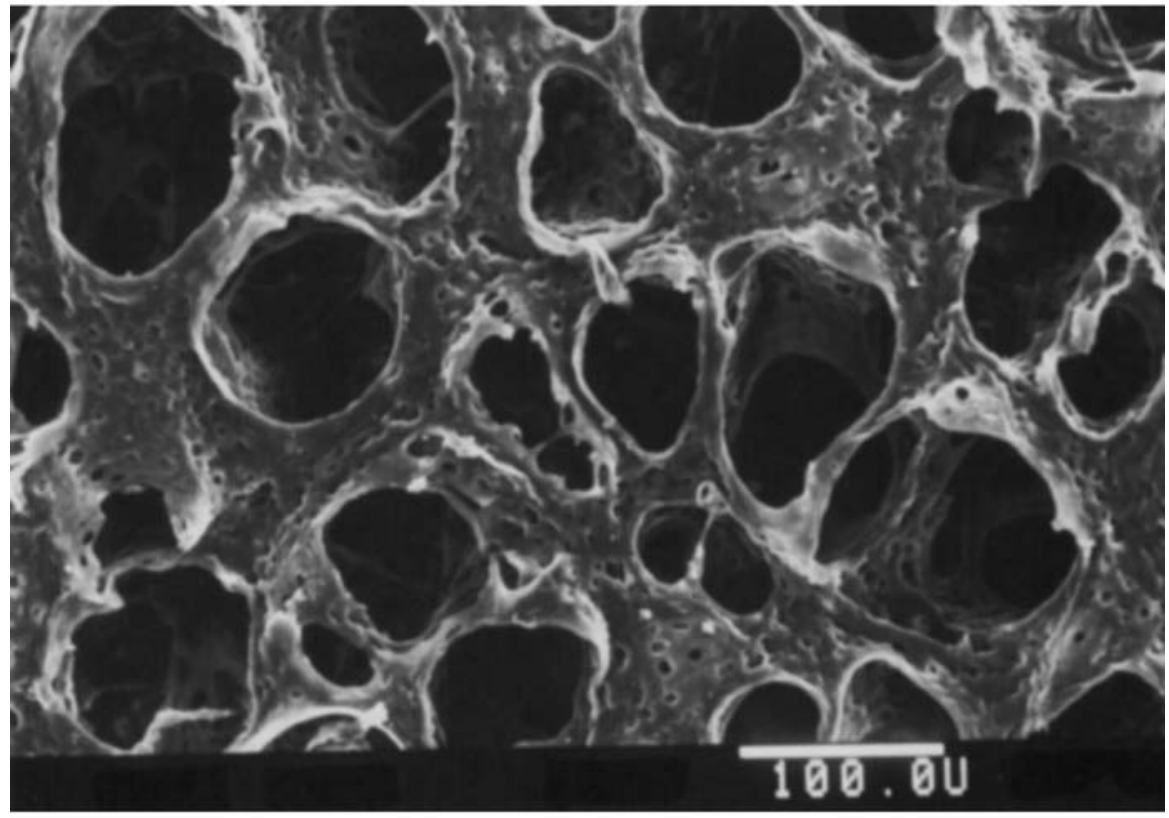

(b)

Figure 3. SEM pictures of the wound dressing prepared by means of the two-step casting process. (a) Top layer. (b) Sublayer. (c) Cross section. 


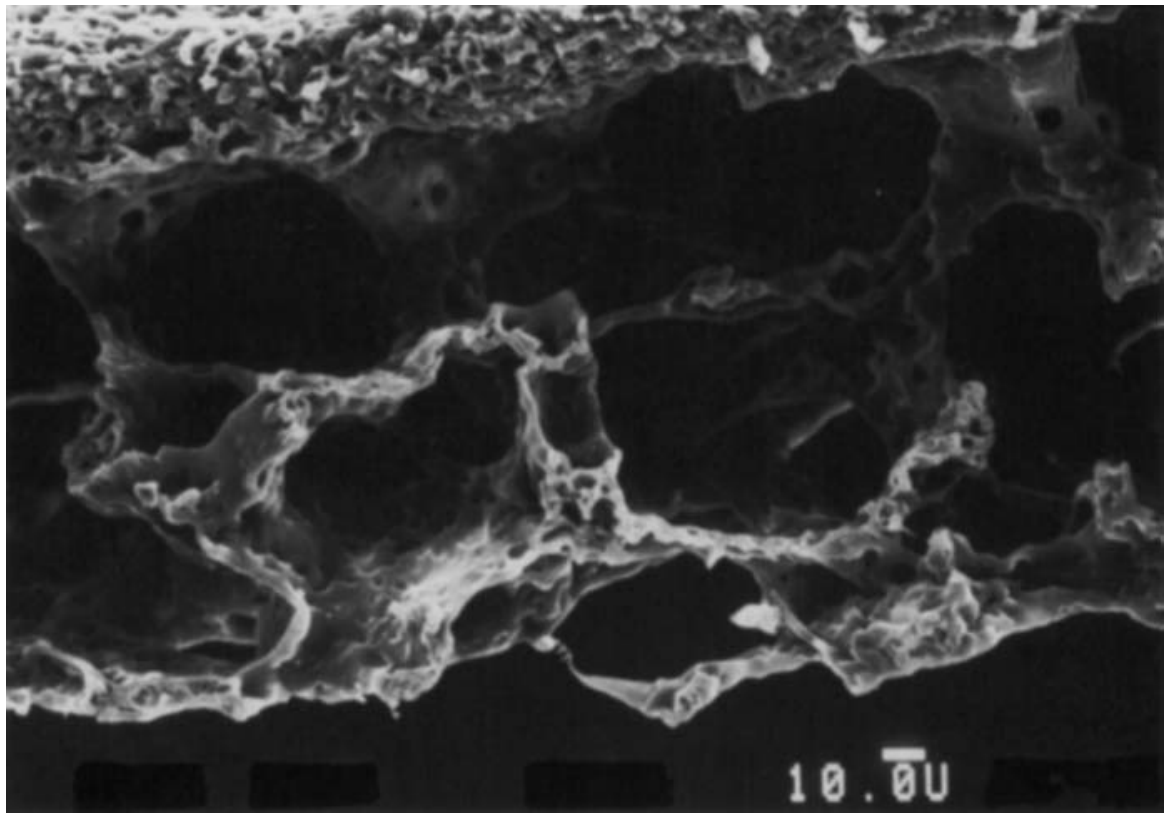

(c)

Figure 3. (continued)

studies that the dense top layers of these asymmetric membranes are formed by gelation of solutions with high polymer concentrations whereas the formation of the porous sublayers is the result of liquid-liquid demixing of solutions with low polymer concentrations. ${ }^{26-29}$ Gelation at the interface of the polymer solution and the coagulation medium takes place because immediately after immersion the inflow of nonsolvent in the polymer film does not keep in pace with the outflow of solvent. An initially higher rate of outflow of the solvent from the polymer film as compared to the rate of inflow of nonsolvent results in an increase of the polymer concentration in the top layer of the polymer film followed by gelation. The nonporous top layer will act as a diffusion barrier for the

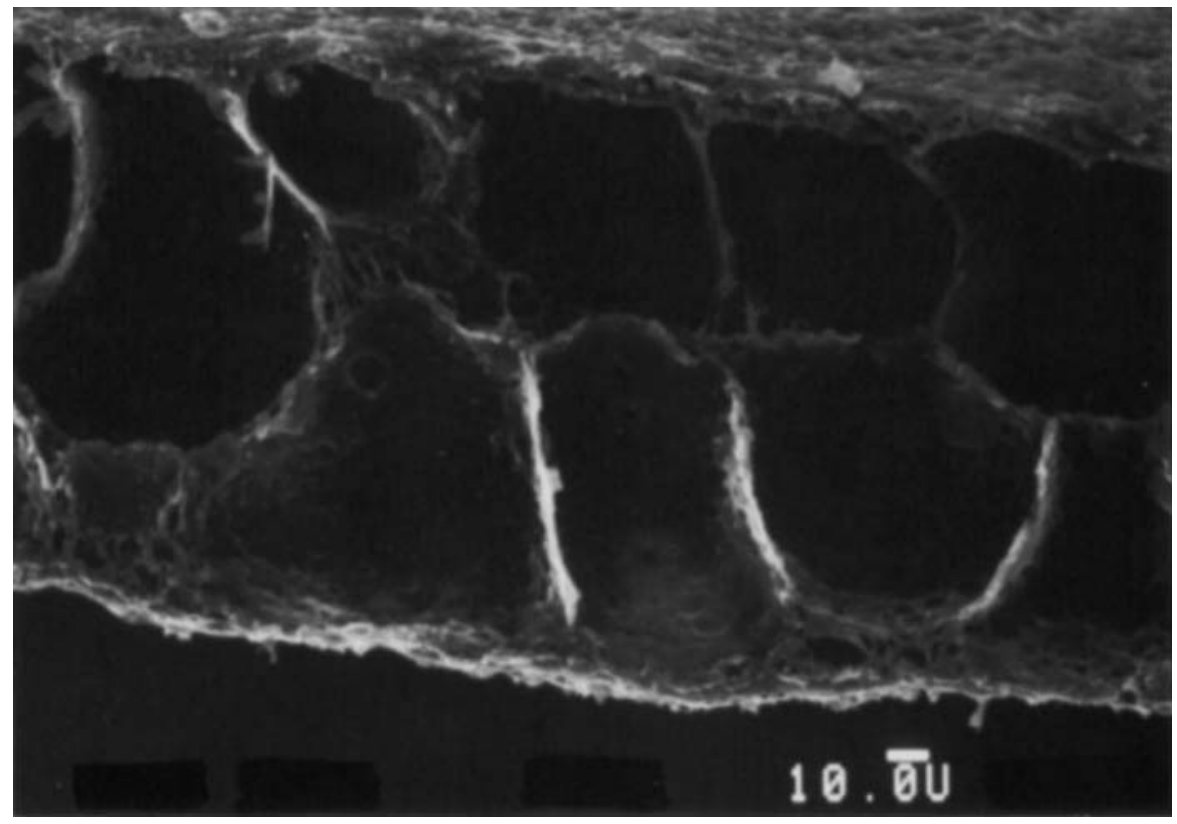

Figure 4. SEM picture of the cross section of a membrane prepared by means of the one-step casting process according to experiment 1 (Table I), showing a dense top layer supported by a sublayer containing isolated macropores. 


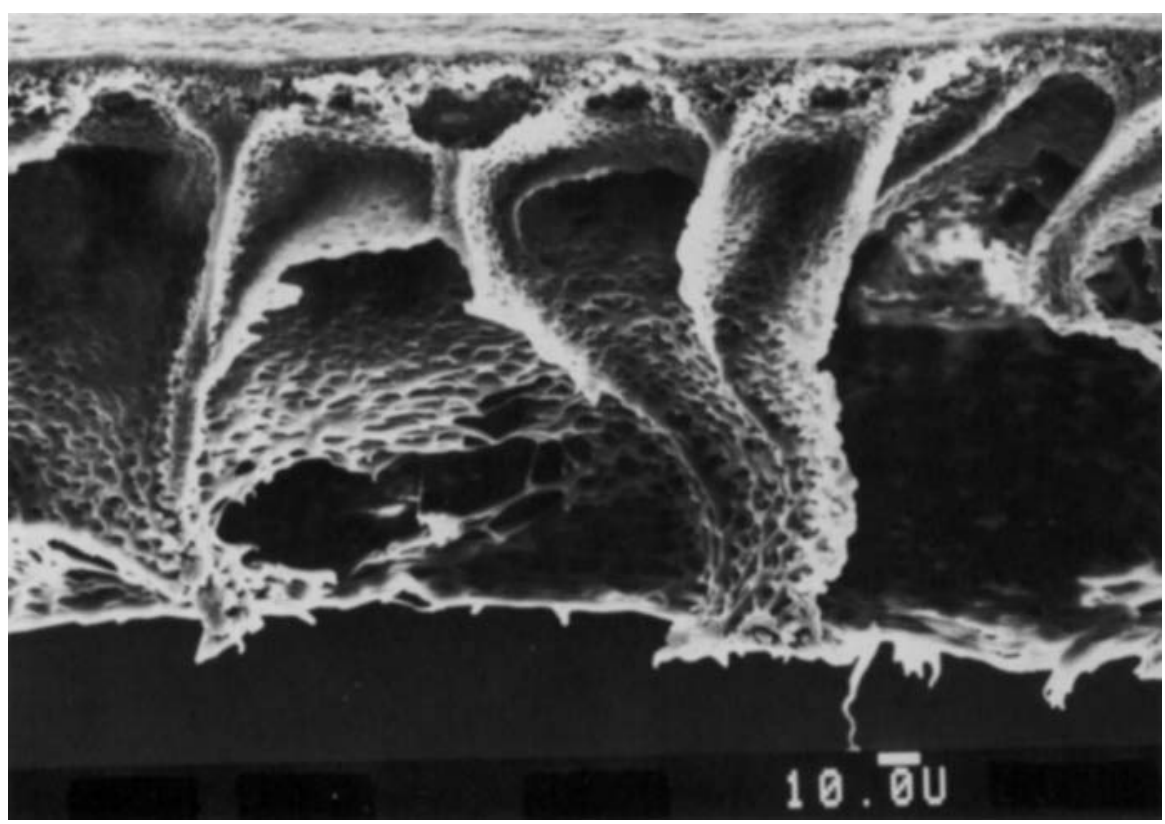

Figure 5. SEM pictures of the cross section of a membrane prepared by means of the one-step casting process according to experiment 5 (Table I), showing a dense top layer supported by a sublayer with an interconnected pore structure containing both macropores and micropores.

transport of both solvent and nonsolvent. However the outflow of solvent is affected to a larger extent than the inflow of nonsolvent. As a consequence, the compositional changes beneath the dense top layer are such that the overall polymer concentration either decreases or remains constant and the nonsolvent/solvent ratio increases which results in liquid-liquid demixing.

The sublayers of the membranes prepared from the three solutions without PVP did not show essential differences and contained isolated macropores (Fig. 4). Neither micropores nor interconnections between the pores were observed. The sublayers of the membranes prepared from the PVP containing solutions had the desired morphology (Fig. 5). These layers consisted of a highly interconnected porous structure also containing micropores. Pore enhancing effects of PVP were also observed by Roesink et al. who studied demixing phenomena of the quarternary system polyether imide(PEI)/PVP/NMP/water. ${ }^{30}$ Enhancement of pore formation was related to a redistribution of PVP over the PEI-rich and PEI-poor domains after the onset of liquid-liquid demixing. Regular PEU membrane structures were obtained using a polymer solution containing both PVP and ethanol. However membranes prepared from a PVP containing polymer solution without ethanol showed macroscopic irregularities and defects such as differences in membrane thickness, pinholes, and tears. This might be caused by differences in the rate of precipitation of the two solutions. Ethanol is a nonsolvent for the polyurethane. Thus with the addition of ethanol less exchange of solvent by nonsolvent is necessary to obtain compositions at which demixing of the system occurs. Therefore the membrane forming process is accelerated and the process is less sensitive for fluctuations in the process conditions.

In the second series of experiments the vapor generator was applied while polymer solutions with the same compositions as in the first series were used. Before immersing cast solutions into the water bath the solutions were exposed for $1.8 \mathrm{~s}$ to a vapor which was saturated with water of $70{ }^{\circ} \mathrm{C}$. Because NMP has a low volatility the compositional changes of the polymer solution during its residence in the vapor gap are mainly determined by the uptake of water from the vapor phase. When a certain minimum amount of water uptake is reached liquid-liquid demixing is expected to occur at the upper layer of the cast solution which may result in the formation of a porous top layer. Because the vapor has a higher temperature than the coagulation bath the polymer solution will have a higher temperature during demixing than when the vapor generator is not used. This will also affect the demixing behavior of the system. However the use of the vapor generator did not affect the structure of the membranes which were prepared from PVP free solutions. These membranes also had dense top layers supported by sublayers which contained isolated macropores. Most likely, not enough water had penetrated into the polymer film to induce liquid-liquid demixing. However since it was recently shown that liquid-liquid demixing does not necessarily result in the formation of porous top layers, the occurrence of liquid-liquid demixing cannot be ruled out. ${ }^{30}$

The application of a polymer solution containing both PVP and ethanol yielded membranes with the desired pore structure [Figs. 6(a-c)]. The sublayer (thickness $150 \mu \mathrm{m}$ ) had a similar appearance as the layer obtained with the 
same polymer solution but without the use of the vapor generator. The layer showed a highly porous structure and contained both macropores $(50-100 \mu \mathrm{m})$ and micropores $(<10 \mu \mathrm{m})$ which were highly interconnected. The top layer (thickness $5-10 \mu \mathrm{m}$ ) consisted of a highly interconnected pore structure $(<1 \mu \mathrm{m})$ which formed a continuous structure with the pores of the sublayer. The size of the interconnections between the pores as determined by bubblepoint measurements was smaller than $0.2 \mu \mathrm{m}$. Membranes prepared from the solution PEU/PVP/NMP $=10 / 5 / 85$ (wt $\%$ ) showed a similar pore structure as membranes prepared from the solution with composition PEU/PVP/NMP/ethanol $=10 / 5 / 65 / 25$ (wt \%). However in the membranes prepared from the solution PEU/PVP/NMP $=10 / 5 / 85(\mathrm{wt} \%)$ irregularities similar to those observed in membranes formed from a polymer solution with the same composition but without the use of the vapor generator were observed. As shown

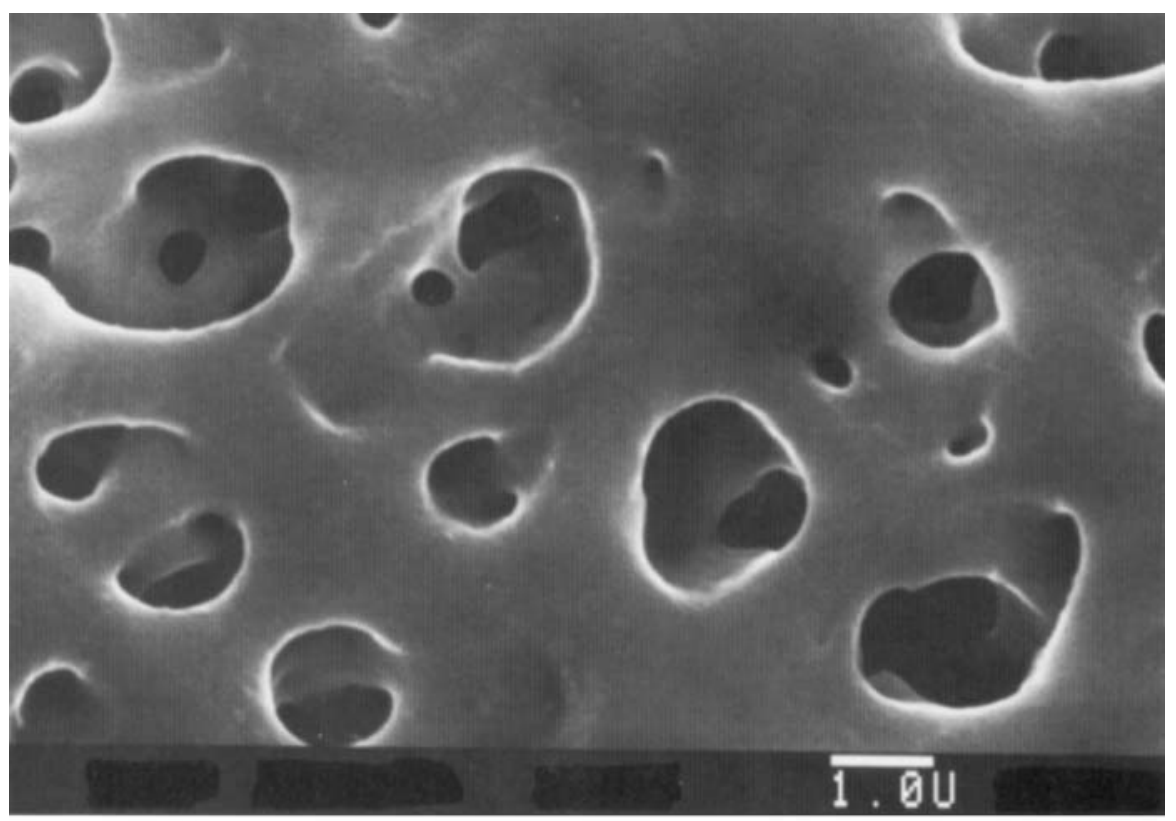

(a)

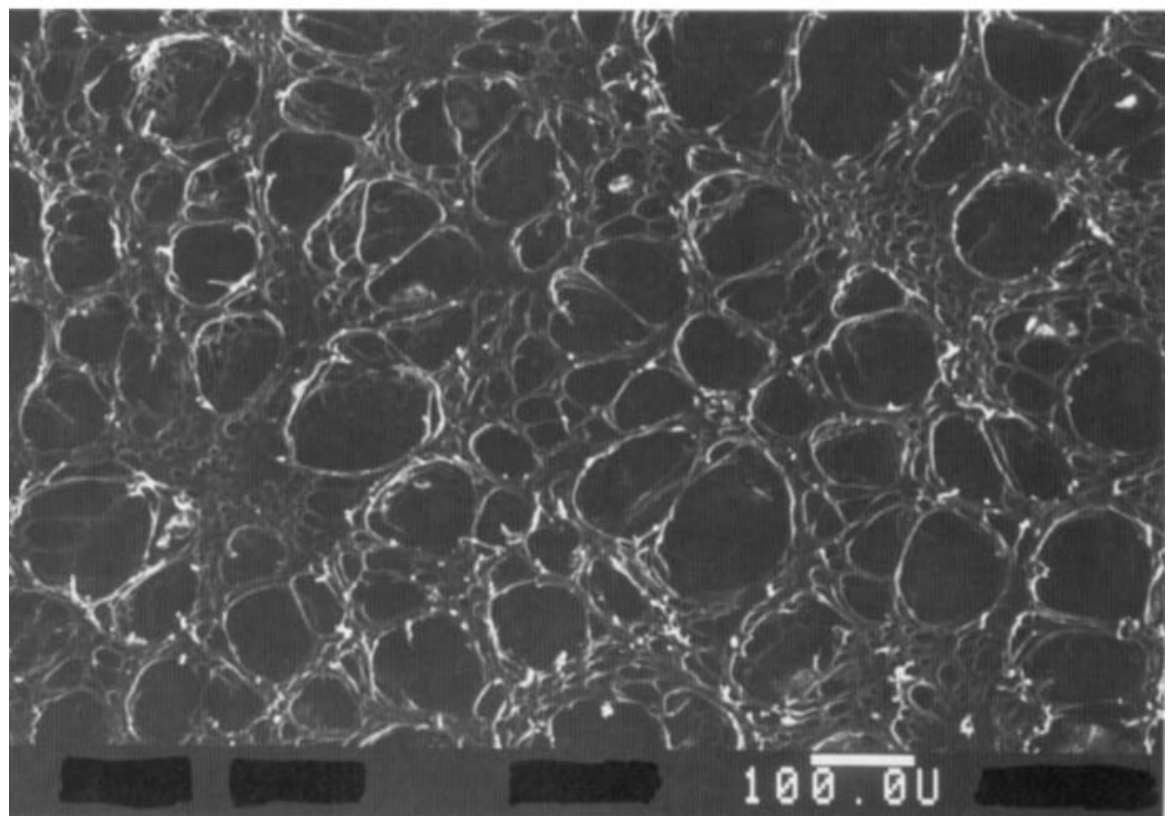

(b)

Figure 6. SEM pictures of the wound dressing prepared by means of the one-step casting process according to experiment 17 (Table I). (a) Top layer. (b) Sublayer. (c) Cross section. 


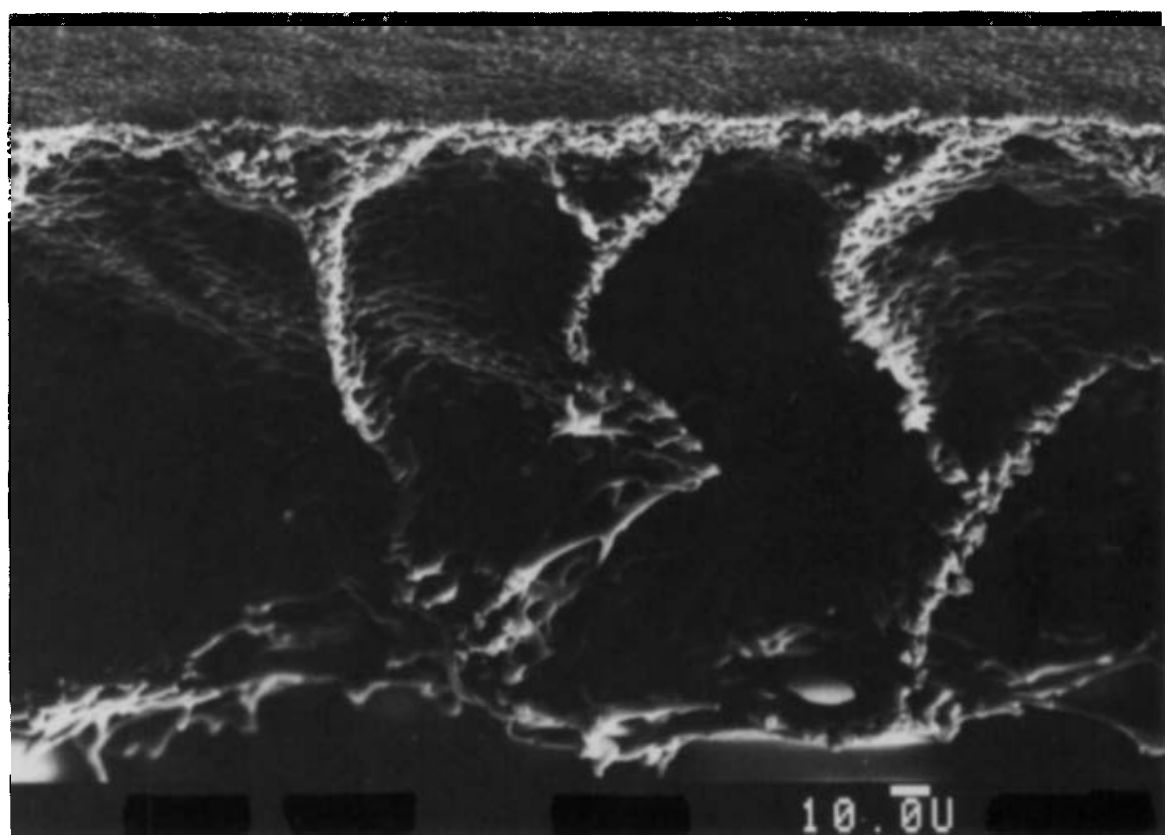

(c)

Figure 6. (continued)

by other investigators the formation of microporous top layers in phase inversion membranes is facilitated by the addition of PVP to the polymer solution. ${ }^{30-33}$ Similar to the formation of the highly interconnected pore structure of the sublayer these phenomena were ascribed to a redistribution of PVP over the membrane matrix after the onset of liquid-liquid demixing. ${ }^{30}$ In our experiments both the addition of PVP to the polymer solution and the exposure of the polymer film to nonsolvent vapor was necessary to obtain microporous top layers. Most likely liquid-liquid demixing was induced by the uptake of water from the vapor phase by the polymer film whereas the formation of micropores was facilitated by presence of PVP in the casting solution.

The effect of exposing the polymer solution to water vapor under different conditions on the pore structure was investigated in more detail. The amount of water vapor penetrating the polymer film could be varied either by changing the water vapor concentration in the vapor gap or by changing the residence time of the polymer film in the vapor gap. In these experiments solutions of composition PEU/PVP/NMP/ethanol $=10 / 5 / 60 / 25$ (wt $\%$ ) were used. The data presented below are the results of two typical series of experiments where either the concentration of water vapor or the residence time was stepwise changed while keeping other process parameters the same.

Variation of the residence time in the vapor gap strongly affected the pore structure [Figs. $7(\mathrm{a}-\mathrm{c})$ show SEM pictures of cross sections of membranes prepared according to experiments 12,13 , and 18 , respectively]. In experiments at which the vapor was kept saturated with water of $70^{\circ} \mathrm{C}$, the maximum pore size in the top layer of the membranes as determined by bubblepoint measurements showed a sigmoid relationship with the residence time of the polymer solution in the vapor gap (Fig. 8). Cross sections of the membranes prepared with a residence time of 12.4 and $32.5 \mathrm{~s}$, respectively, showed symmetric pore structures with only one type of pores. Decreasing the residence time to $8.8 \mathrm{~s}$ resulted in membranes with asymmetric pore structures in which both micropores and macropores in the sublayer could be observed. Furthermore an increase in the density of the macropores was found when the residence time was decreased from 8.8 to $5.1 \mathrm{~s}$. Using residence times shorter than $5.1 \mathrm{~s}$ the density of the macropores in the sublayer remained the same.

Changing the temperature of the water in the vapor generator from $45^{\circ} \mathrm{C}$ to $80^{\circ} \mathrm{C}$ while keeping the residence time of the cast solution in the vapor constant at $1.8 \mathrm{~s}$ a comparable tendency in the pore morphology of the resultant membranes was found as with changing the residence time and keeping the water vapor temperature constant at $70{ }^{\circ} \mathrm{C}$. Saturation of the vapor with water of a temperature between $45^{\circ} \mathrm{C}$ to $65^{\circ} \mathrm{C}$ yielded membranes with dense top layers whereas microporous top layers with a maximum pore size ranging from $0.2 \mu \mathrm{m}$ to $4.3 \mu \mathrm{m}$ were obtained when the temperature was raised from $70^{\circ} \mathrm{C}$ to $85^{\circ} \mathrm{C}$ (Fig. 9). The sublayers of the membranes obtained using vapor which was saturated with water of $48{ }^{\circ} \mathrm{C}$ to $70{ }^{\circ} \mathrm{C}$ showed both micropores and macropores with a high density of the macropores. Raising the temperature from $70^{\circ} \mathrm{C}$ to $85^{\circ} \mathrm{C}$ yielded comparable structure, however, the density of the macropores was decreased.

Macropore formation is a phenomenon often observed in the preparation of immersion precipitation membranes. 
Recently Reuvers ${ }^{34}$ showed that the formation of macropores is facilitated when the polymer solution demixes instantaneously after immersion of the polymer solution into a nonsolvent. It was proposed that the macropores originate from the growth of droplets of the polymerpoor phase which are formed by liquid-liquid demixing. Due to the fast demixing process the interface between the polymer solution and the coagulation bath acts as a barrier for the exchange of solvent by nonsolvent. As a result the solvent content of the sublayer remains relatively high and the nonsolvent content relatively low. This causes a delay in the gelation of the polymer-rich phase allowing the droplets of the polymer-poor phase to grow which finally results in the formation of large

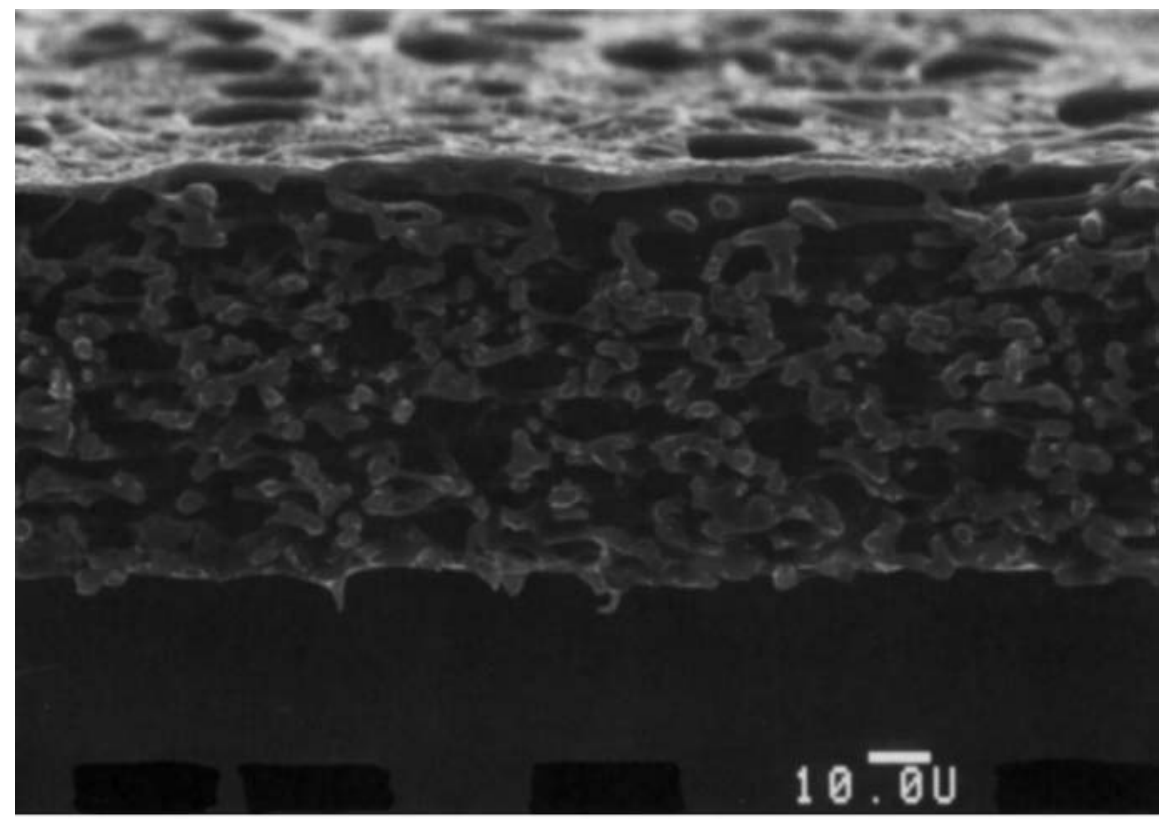

(a)

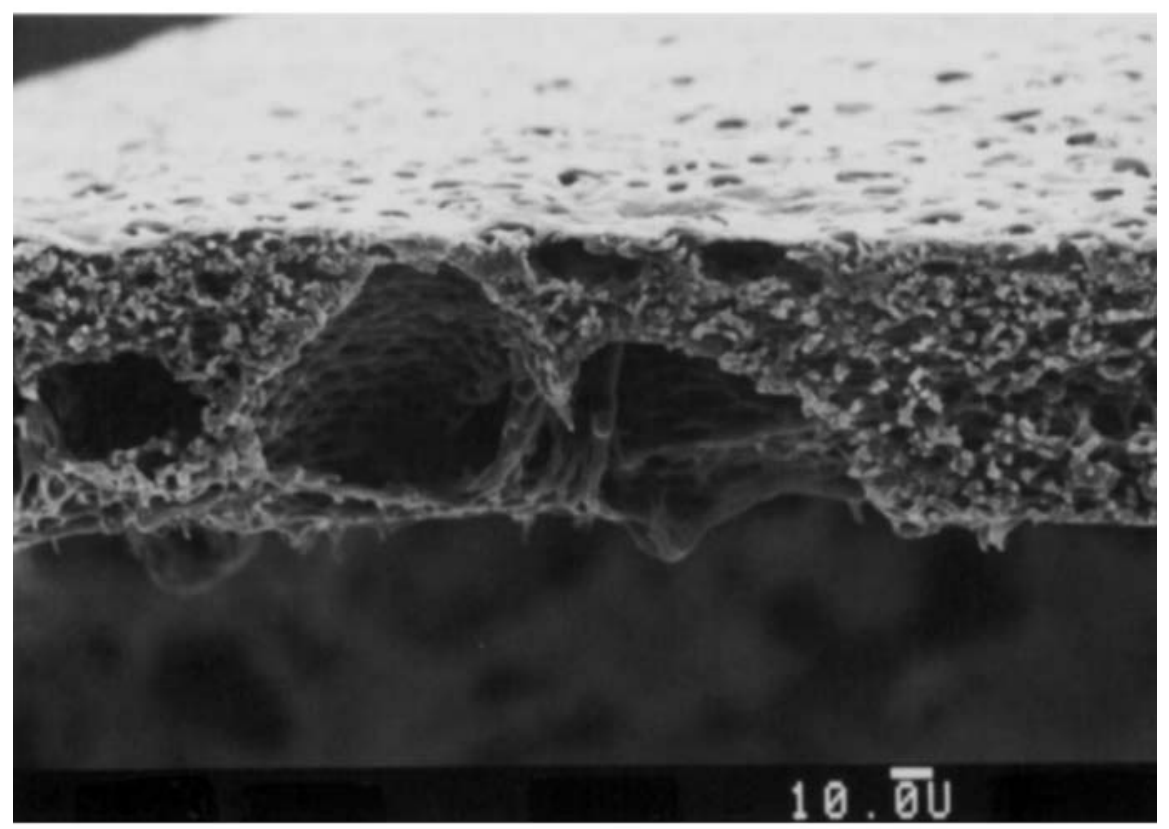

(b)

Figure 7. SEM pictures of cross sections of membranes prepared by means of the one-step casting process with different residence times in the vapor gap. (a) Residence time: $12.4 \mathrm{~s}$ (experiment 12, Table I). (b) Residence time: $8.8 \mathrm{~s}$ (experiment 13, Table l). (c) Residence time: $1.4 \mathrm{~s}$ (experiment 18, Table I). 


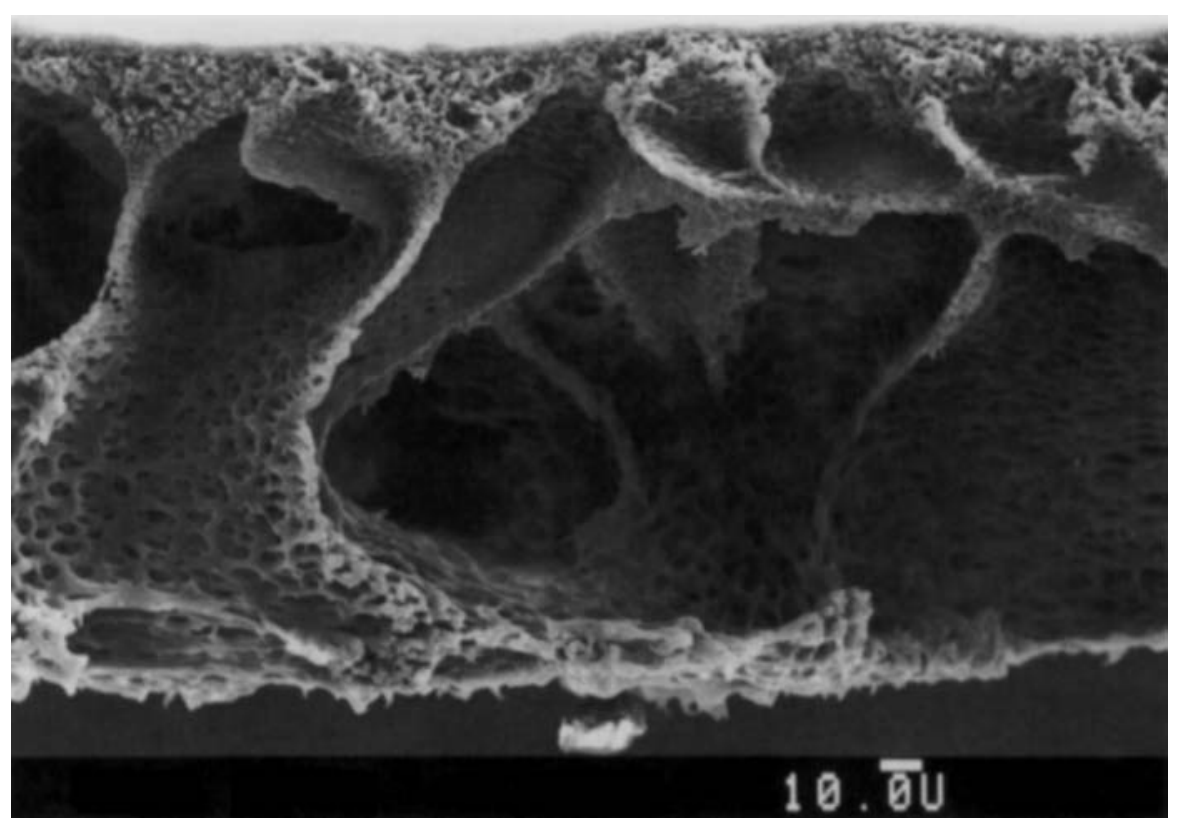

(c)

Figure 7. (continued)

pores. Since NMP and water have a good interaction, an instantaneous demixing can be expected when the PEU/PVP/NMP/ethanol solution is immersed into the water bath. Therefore the high density of macropores in the sublayers of the membranes which were prepared with a residence time shorter than $5.1 \mathrm{~s}$ in the vapor gap using vapor saturated with water of $70{ }^{\circ} \mathrm{C}$ or a residence time of $1.8 \mathrm{~s}$ using vapor saturated with water of a temperature lower than $70^{\circ} \mathrm{C}$ can be explained with this mechanism.

However a different situation occurs when the polymer solution is exposed to water vapor for extended periods of time or when the vapor is kept saturated with water

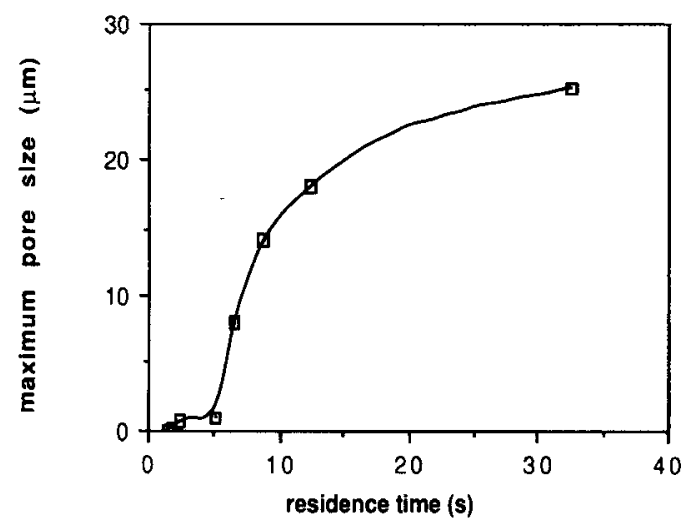

Figure 8. Maximum pore size in the top layer of membranes prepared by means of the one-step casting process as determined by bubblepoint measurements versus the residence time in the vapor gap. The maximum pore sizes are the means of two measurements performed on two different samples randomly taken from each membrane. The error was maximally $15 \%$. (The membranes were prepared according to experiments $11-18$, Table I). of higher temperatures. With residence times of 12.4 and $32.5 \mathrm{~s}$, respectively, and using vapor saturated with water of $70{ }^{\circ} \mathrm{C}$ symmetric pore structures were obtained. These types of pore structures are usually formed with complete phase inversion from the vapor phase. ${ }^{21,25}$ Therefore it can be assumed that the water vapor had penetrated through the whole film resulting in complete demixing of the system before the film had entered the coagulation bath. Differences in pore size can be explained by temperature effects. When the temperature of the polymer solution is raised, gelation of the polymer-rich phase will take place at higher polymer concentrations. Therefore at higher

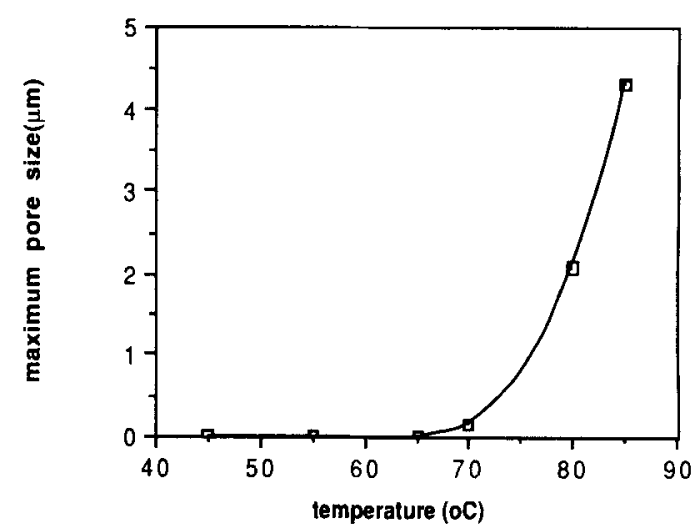

Figure 9. Maximum pore size in the top layer of membranes prepared by means of the one-step casting process as determined by bubblepoint measurements versus the saturation temperature of the water in the vapor gap. The maximum pore sizes are the means of two measurements performed on two different samples randomly taken from each membrane. The error was maximally $15 \%$. (The membranes were prepared according to experiments $19-23$, Table I). 
temperatures the droplets of the polymer-poor phase will grow to larger volumina resulting in larger pores. Thus increasing the residence time in the vapor gap will result in an increased temperature of the polymer solution which leads to increased pore sizes. Using vapor saturated with water of $70^{\circ} \mathrm{C}$ and a residence time in the vapor gap between 5.1 and $12.4 \mathrm{~s}$ or using vapor saturated with water of a temperature higher than $70{ }^{\circ} \mathrm{C}$ and a residence time in the vapor gap of $1.8 \mathrm{~s}$ both resulted in the formation of membranes with intermediate structures. Apparently the water from the vapor phase had penetrated through the whole polymer solution locally resulting in parts with symmetric pore structures whereas in other parts of the polymer film macropores were formed by the mechanism as described above.

The maximum pore size in the top layer showed a clear relationship with the amount of water taken up from the vapor phase which was varied either by changing the residence time or water concentration in the vapor gap. This might be caused by the fact that with an increased water uptake the system demixes at a decreased polymer concentration although also the temperature effects as described above might play a role.

In conclusion, a membrane with the desired pore structure can be prepared by means of the one-step casting process using a solution of composition PEU/PVP/ $\mathrm{NMP} / \mathrm{ethanol}=10 / 5 / 60 / 25(\mathrm{wt} \%)$. Both the addition of PVP to the polymer solution and the exposure of the polymer solution to water vapor before immersion in the coagulation bath are essential to obtain a microporous top layer. The residence time, the water concentration and/or the temperature in the vapor gap strongly affects the pore structure. Using short residence times and/or vapor saturated with water of low temperatures results in membranes with dense top layers whereas the use of long residence times in the vapor gap and/or vapor saturated with water of high temperatures leads to membranes with too large pores in the top layer and a too low density of macropores in the sublayer.

\section{PVP Content of the Membranes}

In the one-step procedure PVP was used as an enhancer for pore formation. PVP is a water soluble polymer. However it is known that with the preparation of phase inversion membranes using PVP containing solutions and water as coagulation medium a substantial amount of PVP becomes entrapped in the membrane matrix. ${ }^{30-33}$

The residual amount of PVP in the membrane which was prepared from a solution with composition $\mathrm{PEU} / \mathrm{PVP} / \mathrm{NMP}=10 / 5 / 85(\mathrm{wt} \%)$ and immersed in water of $20{ }^{\circ} \mathrm{C}$ was $8.3 \pm 1.2 \mathrm{wt} \%$. The PVP content of a membrane which was prepared from a solution whereby $25 \mathrm{wt} \%$ of NMP was substituted by ethanol did not differ $(8.4 \pm 0.5 \mathrm{wt} \%)$. In contrast, the PVP content of the membrane was decreased to $5.8 \pm 0.7 \mathrm{wt} \%$ when the extraction procedure was carried out in water of $48{ }^{\circ} \mathrm{C}$ instead of $20^{\circ} \mathrm{C}$. The same value for the residual amount of PVP $(6.1 \pm 0.4 \mathrm{wt} \%)$ was found when the membrane was immersed in water first for 2 weeks at $20{ }^{\circ} \mathrm{C}$ and thereafter for 2 weeks at $48{ }^{\circ} \mathrm{C}$.

During the precipitation process there is an exchange of solvent by nonsolvent. PVP will partly dissolve in the coagulation medium and will be partly entrapped in the precipitated polyurethane. Therefore the amount of PVP remaining in the PEU-matrix will depend on the demixing process and the interaction of PVP and PEU. Addition of ethanol to the casting solution will influence the demixing process but no change in the residual amount of PVP in the membrane was observed. Moreover diffusion of PVP from the membrane is a very slow process as compared to the precipitation of the polyurethane. Furthermore when the temperature of the extraction medium is raised after 2 weeks from $20^{\circ} \mathrm{C}$ to $48{ }^{\circ} \mathrm{C}$, the same PVP content of the membrane is found after again 2 weeks as compared to an extraction period of 2 weeks at $48{ }^{\circ} \mathrm{C}$ only. These results indicate that the final content of PVP in the membrane is mainly determined by the interaction between PVP and PEU.

Ethanol is a good solvent for PVP and a swelling agent for PEU. Therefore it can be hypothesized that the diffusion of PVP is facilitated when the membrane is immersed in ethanol. However after 2 weeks of extraction in water of $48{ }^{\circ} \mathrm{C}$, no further decrease of the PVP content of the membrane was measured when the membrane was immersed in ethanol of $48{ }^{\circ} \mathrm{C}$ for an additional period of 2 weeks (residual amount of PVP in the membrane $5.5 \pm$ $0.7 \mathrm{wt} \%$ ). Apparently, the interaction between ethanol and PEU is not strong enough to interfere with the interaction between PEU and PVP.

Since the wound dressing is prepared by immersion of a polymer solution of composition PEU/PVP/NMP/ ethanol $=10 / 5 / 60 / 25(\mathrm{wt} \%)$ into a water bath of $48{ }^{\circ} \mathrm{C}$ it can be concluded that the wound dressing is composed of $\mathrm{PEU} / \mathrm{PVP}=94 / 6(\mathrm{wt} \%)$.

\section{Mechanical Properties}

Force strain measurements using samples of $10 \times 10 \mathrm{~mm}$ were performed to characterize the mechanical properties of the two types of polyurethane wound dressings. (Typical force-strain curves are shown in Fig. 10). The wound dressing prepared by means of the two-step casting process broke at an elongation of $1030 \pm 60 \%$ and a force of $670 \pm 40 \mathrm{~N}(n=3)$ whereas an elongation at break of $410 \pm 30 \%$ and a force of $140 \pm 15 \mathrm{~N}$ were found for the wound dressing prepared by means of the onestep casting process $(n=3)$. The differences between these values may be explained as follows. Firstly, both types of wound dressings consist of a microporous top layer supported by a highly porous sponge-like sublayer containing both macropores and micropores. However as can be seen from the SEM photographs in Figures 3 and 6 , there are pronounced differences in pore morphology, porosity, and thickness of the top layer. These characteristics will strongly affect the mechanical properties 
of the wound dressing. Secondly, the starting materials for the preparation of the two types of wound dressing, Biomer $^{\circledR}$ and Pellethane ${ }^{\circledR} 2363$ 80AE, differ in their mechanical properties. This will be expressed in the mechanical properties of the wound dressing as well. Moreover a substantial amount of PVP is present in the wound dressing prepared by means of the one-step casting process which will also affect the mechanical properties of the wound dressing.

Despite the differences in the mechanical properties, we have observed that both types of wound dressings are sufficiently elastic to be applicable near joints or at other flexing wound surfaces.

\section{Drainage Capacity}

The in vitro serum permeability test yielded a specific drainage capacity of $0.094 \mathrm{~mL} \mathrm{~s}^{-1} \mathrm{~cm}^{-2} \mathrm{~cm}$ serum $^{-1}$ for the wound dressing prepared by means of the two-step process, $0.122 \mathrm{~mL} \mathrm{~s}^{-1} \mathrm{~cm}^{-2} \mathrm{~cm}$ serum ${ }^{-1}$ for the wound dressing prepared by means of the one-step process, and $0.029 \mathrm{~mL} \mathrm{~s}^{-1} \mathrm{~cm}^{-2} \mathrm{~cm}$ serum ${ }^{-1}$ for Biobrane ${ }^{\circledR}$. These values were constant for a column height of serum between 1 and $12 \mathrm{~cm}$. The high drainage capacity of both types of polyurethane wound dressings can be explained by the fact that the micropores in the top layers are interconnected. Therefore multiple channels are formed which allow the flow of fluids from the macropores of the sublayer through the micropores in the top layer. The pinholes in Biobrane ${ }^{\circledR}$ also allow drainage. However, the density of the pinholes is much lower which results in a lower drainage capacity than the two types of polyurethane wound dressing.

Analogous to differences between the mechanical properties, differences between the drainage capacity of the two types of polyurethane wound dressings can be ascribed to differences in pore morphology and differences in the hydrophilicity of the starting materials. Furthermore

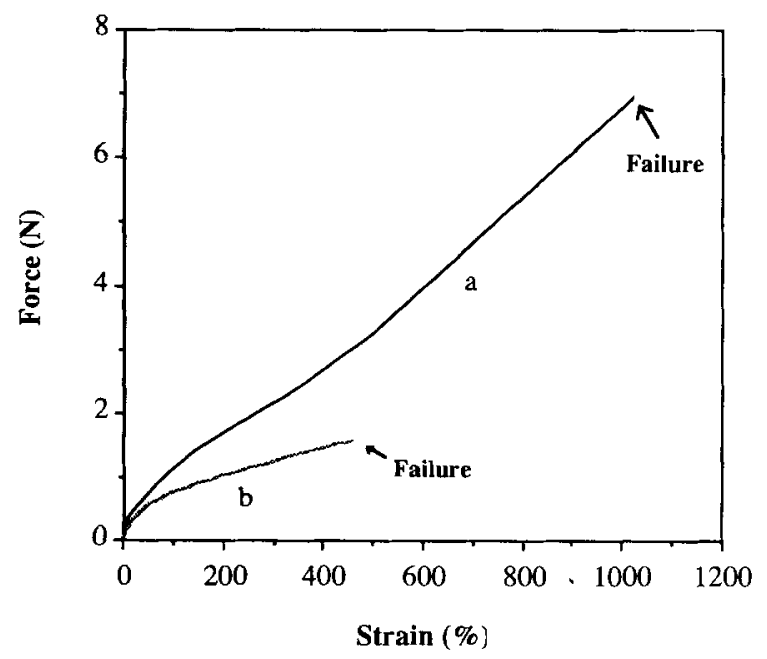

Figure 10. Force-strain curves of the wound dressing made by means of the two-step casting process (a) and by means of the one-step casting process $(b)$. it is known from literature that phase inversion membranes become more hydrophilic when PVP is present in the casting solution. ${ }^{30}$ Therefore the presence of a substantial amount of PVP in the wound dressing prepared by means of the one-step process will contribute considerably to the observed higher drainage capacity as compared to the wound dressing prepared by means of the two-step process.

\section{Bacteriology}

The in vitro bacteriologic test showed that the wound dressing prepared by means of the two-step casting process can successfully prevent penetration of bacteria. In 29 out of 30 occasions the agar plates were free of bacterial contamination. Bacterial penetration did not occur despite the fact that the maximal pore size at the surface of the wound dressing $(0.7 \mu \mathrm{m})$ is larger than the minimal size of the bacteria $\left(0.5 \mu \mathrm{m}^{35}\right)$. Most likely, the interconnections between the pores in the top layer are smaller than $0.5 \mu \mathrm{m}$. Bacterial contamination in one occasion was probably due to the use of an imperfect sample with too large pores. Biobrane ${ }^{\circledR}$ was considerably less effective in preventing the penetration of bacteria. In 11 out of 30 occasions the agar plates showed bacterial contamination. Apparently, the pinholes in this wound dressing are large enough to allow the passage of bacteria.

\section{In vivo Experiments}

The applicability of the wound dressing prepared by means of the two-step casting process was evaluated using full thickness skin defects created on the backs of guinea pigs. Biobrane ${ }^{\circledR}$ was used as a reference material.

Immediately after application the polyurethane wound dressing as well as Biobrane ${ }^{\circledR}$ adhered firmly to the wound surface. ${ }^{15}$ After 3 days of application small fluid filled pockets were observed beneath Biobrane ${ }^{\circledR}$. The fluid filled pockets became purulent indicating infections and were enlarged in time. This process ultimately lead to detachment of the dressing from the wound surface between 5 and 14 days after application in all cases. In contrast, adherence of the polyurethane wound dressing to the wound surface was retained during the whole process of wound healing ( 7 weeks). When only the microporous top layer was applied to the skin defect a dramatic decrease of adherence was found (data not shown). This indicates that the adhesion forces are mainly determined by the specific structure of the sublayer. The interaction between the skin substitute and the skin defect can be ascribed to three different mechanisms. Immediately after application the wound dressing became tightly bound to the wound surface by capillary forces exerted by the interconnected micropores of both layers. Subsequently fibrin was deposited into the macroporus structure. Because of its sponge-like structure the sublayer has a large and good contact area for fibrin interconnections with the wound surface. Disruptions of interconnections most likely fibrin 
are clearly visible at the wound surface from which the wound dressing was pulled loose after $5 \mathrm{~h}$ of application (Fig. 11). Finally the sublayer containing relatively large macropores $(50-100 \mu \mathrm{m})$ allowed ingrowth of tissue (Fig. 12). This resulted in an even stronger adherence.

Immediately after application wound exudate passed through the wound dressing. In time the passage of wound exudate through the material subsided and a dry protein crust was formed as a result of water evaporation at the top layer of the wound dressing. This crust blocked the micropores in the top layer which resulted in a decrease of the permeability of the wound dressing. However during the entire time of wound healing accumulation of fluids beneath the dressing was never observed. Immediately after injuring the skin the wound goes through an exudative phase which requires a high drainage capacity of the wound dressing. However when the production of exudate subsides, the permeability of the dressing should be reduced to prevent wound dehydration. Our experiments showed that the interconnected micropores in the top layer form a selfregulating system for fluid drainage. The micropores remain open as long as wound exudate is produced, but become occluded at the moment the production of exudate stops and the drainage of fluids is not required anymore. Therefore in none of the cases wound dehydration was observed. Furthermore the wound dressing was effective in preventing the penetration of microorganisms because wound infections never occurred.

The wound dressing became translucent after application. Therefore the wound could be inspected without removing the wound dressing. The healing of the wound occurred by the formation of granulation tissue beneath the wound dressing and the outgrowth of epidermis from the wound edges between the granulation tissue and the wound dressing (Fig. 12). The regeneration of the epidermis was accompanied with a gradual and spontaneous detachment of the dressing from the healed skin. No polyurethane particles were observed in the regenerated epidermis.

It can be concluded from the results of the application of wound dressing prepared by means of the two-step casting process for full thickness skin defects created on the backs of guinea pigs that the wound dressing is permeable enough to allow an effective drainage of wound exudate and that it is sufficiently occlusive to prevent the penetration of microorganisms and wound dehydration. Furthermore the wound dressing remained firmly adhered to the wound surface and could be left on the wound until full regeneration of the skin was achieved.

In preliminary studies, it was shown that the polyurethane wound dressing prepared by means of the two-step as well as by means of the one-step casting process can be applied successfully at split skin donor sites on patients.

The applicability of the wound dressing prepared by means of the one-step casting process to other clinical wound types is currently under evaluation.

This study was financially supported by the Dutch Technology Foundation (STW) and Koninklijke Utermöhlen N.V. (Utrecht, The Netherlands). The authors wish to thank D. M. Koenhen and H. D. W. Roesink (X-Flow, Almelo, The Netherlands) for the enlightening discussions concerning phase inversion processes and H. L. Bartels (Central Animal Laboratory, University of Groningen, Groningen, The Netherlands) for his surgical assistance.

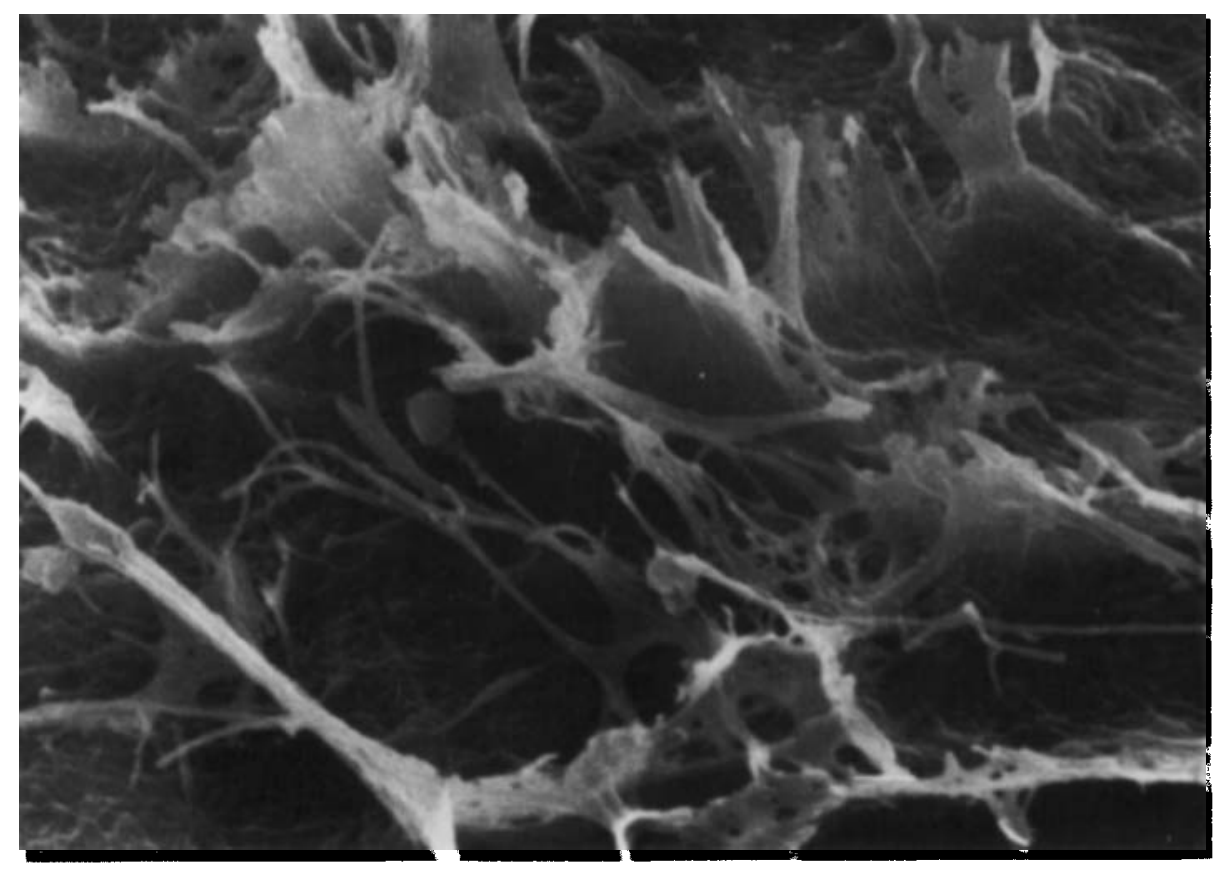

Figure 11. SEM picture of the wound surface from which the polyurethane wound dressing prepared by means of the two-step casting technique was pulled loose after $5 \mathrm{~h}$ of application showing a disrupted fibrous structure most probably consisting of fibrin (magnification $\times 8000$ ). 


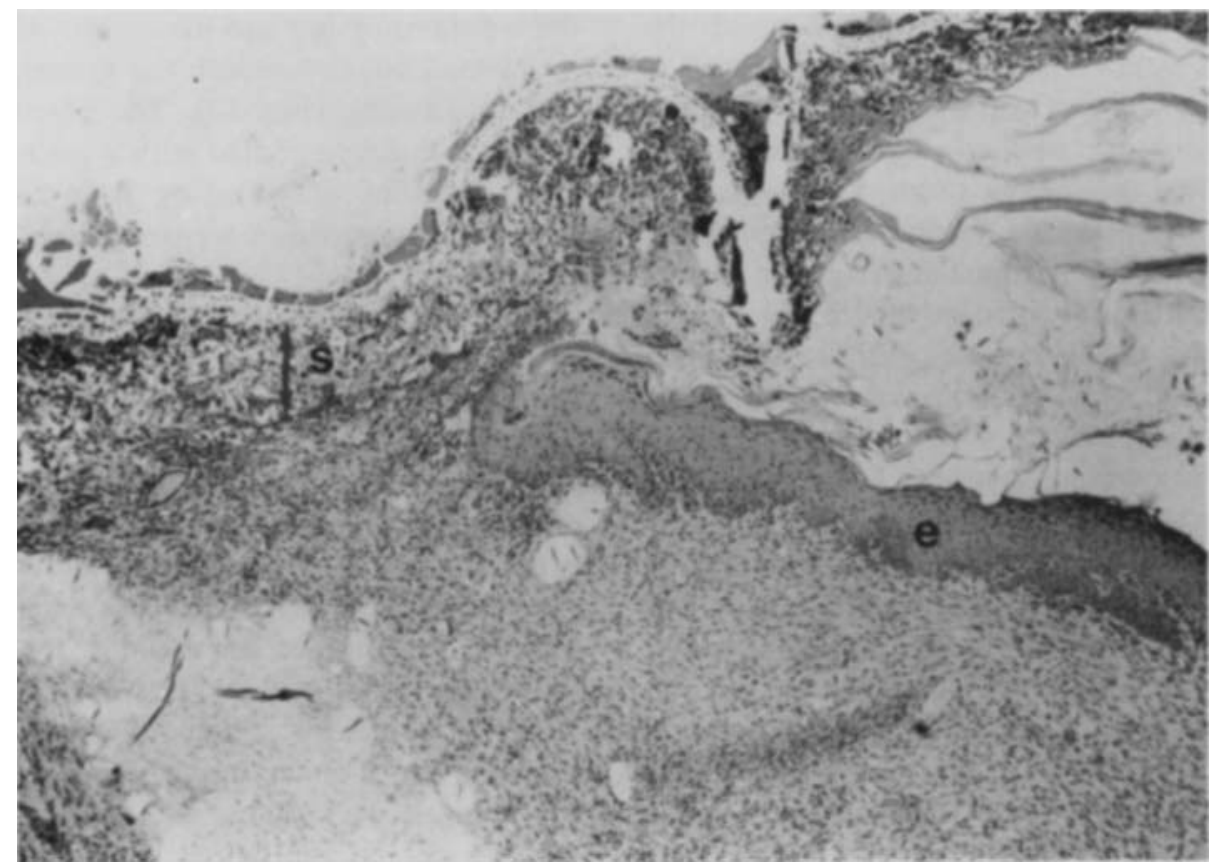

Figure 12. LM picture of a full thickness skin defect treated with the polyurethane wound dressing prepared by means of the two-step casting technique after 5 weeks of application showing ingrowth of tissue into the sublayer (s) of the wound dressing, regeneration of the epidermis (e) between the granulation tissue and the wound dressing, and a spontaneous detachment of the wound dressing after epidermization (magnification $\times 60$ ).

\section{REFERENCES}

1. Brochures of commercially available wound dressings and skin substitutes: Biobrane ${ }^{(}$, Coldex $^{\circledR}$, Duoderm ${ }^{\circledR}$, Epigard $^{\circledR}$, Lyofoam $^{(}$, Omiderm $^{\circledR}$, Opsite ${ }^{\circledR}$, Spandre $^{(}$, Surfasoft ${ }^{\circledR}$.

2. May, S. R, Physiology, immunology, and clinical efficacy of an adherent polyurethane wound dressing. In: Wise, D. L., ed. Burn wound coverings. Vol. 2. Boca Raton, FL, CRC Press; 1984:53-78.

3. Behar, D.; Juszynski, M.; Ben Hur, N.; Eldad, A.; Tuchman, Y.; Sterenberg, N.; Rudensky, B. Omiderm, a new synthetic wound covering: physical properties and drug permeability studies. J. Biomed. Mater. Res. 20:731-738; 1986.

4. Park, G. B. Burn wound coverings-A review. Biomat., Med. Dev. Art. Org., 6:1-35; 1978.

5. Quinn, K. J.; Courtney, J. M.; Evans, J.H.; Gaylor, J. D. S.; Reid, W.H. Principles of burn dressings. Biomaterials $6: 369-377 ; 1985$.

6. Cristofoli, C.; Lorenzini, M.; Furlan, S. The use of Omiderm, a new skin substitute, in a burn unit. Burns 12:587; 1986.

7. Woodroof, E. A., Biobrane ${ }^{\circledR}$, a biosynthetic skin prosthesis. In: Wise, D. L., ed. Burn wound coverings. Vol. 2. Boca Raton, FL: CRC Press; 1984:1-25.

8. de Riel, S. Assessment of burn wound therapy systems. In Wise, D. L., ed. Burn wound coverings. Boca Raton, FL: CRC Press; 1984:1-37.

9. O'Neill, J.A. Comparison of xenograft and prosthesis for burn wound care. J. of Pediatric. Surg. 8:705-709; 1973.

10. Alexander, J. W.; R. C. Rooney, L. M.; McDonald, J. J.; MacMillan, B.G. Clinical evaluation of Epigard, a new synthetic substitute for homograft and heterograft skin. J. of Trauma 13:374-383; 1973 .

11. Gogolewski S.; Pennings, A.J. Biodegradable materials of polylactides, 4a. Porous biomedical materials based on mix- tures of polylactides and polyurethanes. Macromol. Chem. Rapid. Commun. 3:839-845; 1982.

12. Gogolewski, S.; Pennings, A. J. An artificial skin based on biodegradable mixtures of polylactides and polyurethanes for full thickness skin wound covering. Makromol. Chem. Rapid. Commun. 4:675-680; 1983.

13. Larkin, R. L.; Kupel, R.E. Quantitative analysis of polyvinyl pyrrolidone in atmosphere samples and biological tissues. Amer. Ind. Hyg. Assoc. J. 26:558-561; 1983.

14. Schchori, E.; Jagur-Grodzinski, J. Polymeric alloys of poly(vinylpyrrolidone) with a macrocyclic polyetherpolyamide. J. Appl. Polym. Sci. 20:1665-1671; 1970.

15. Lommen, E.J.C.M.P. Artificial skin. The Netherlands: University of Groningen; 1988. Dissertation.

16. Coury, A.J.; Stokes, K. B.; Cahalan, P.T.; Slaikeu, P.C. Biostability considerations for implantable polyurethanes. Life Support Syst. 5:25-39; 1987.

17. Stokes, K. B.; Chem, B. Polyether polyurethanes: biostable or not? J. of Biomater. Appl. 3:228-259; 1988.

18. Lelah, M. D.; Cooper, S. L. Polyurethanes in medicine, Boca Raton, FL: CRC Press; 1986.

19. McMillin, C.R. Elastomers in biomedical applications: an overview of types and end-uses. Elastomers 120:22-27; 1988.

20. Coury, A.J.; Slaikeu, P. C.; Cahalar, P.T.; Stokes, K. B. Medical applications of implantable polyurethanes: current issues. Progr. Rubber. Plast. Techn. 3:24-37; 1987.

21. Kesting, R.E. Synthetic polymer membranes. New York: McGraw-Hill; 1972.

22. Strathman, H.; Kock, $K$. The formation mechanism of phase inversion membranes. Desalination 21:241-255; 1977.

23. Pusch, W.; Walch, A. Synthetic membranes-preparation, structure and application. Angew. Chem. Int. Ed. Eng. $21: 660-685 ; 1982$.

24. Frommer, M.A.; Lancet, D. The mechanism of membrane formation: membrane structures and their relation to prepa- 
ration conditions. in: Lonsdale, H.K.; Podall, H.E., eds. osmosis membrane research. New York: Plenum Press; 1972:85-110.

25. Strathmann, $\mathbf{H}$. Production of microporous media by phase inversion processes. In: Lloyd, D. R., ed. Material science of synthetic membranes. ACS Symp. Ser.; Am. Chem. Soc., Washington, DC, 1985:165-195.

26. Wijmans, J. G.; Baaij, J.P.B.; Smolders, C.A. The mechanism of formation of microporous or skinned membranes produced by immersion precipitation. J. Membr. Sci. 14:263-274; 1983.

27. Broens, L.; Altena, F. W.; Smolders, C. A.; Koenhen, D. M. Asymmetric structures as a result of phase separation phenomena. Desalination 32:33-45; 1980.

28. Koenhen, D. M.; Mulder, M. H. V.; Smolders, C. A. Phase separation phenomena during the formation of asymmetric membranes. J. Appl. Polym. Sci. 21:199-215; 1977.

29. Bokhorst, H.; Altena, F. W.; Smolders, C. A. Formation of asymmetric cellulose acetate membranes. Desalination $31: 349-360 ; 1981$.

30. Roesink, H. D. W. Microfiltation. Membrane development and module design. Enschede, The Netherlands: University of Twente; 1989. Dissertation.

32. Cabasso, I.; Klein, E.; Smith, J.K. Polysulfone hollow fibers. 1. Morphology. J. Appl. Polym. Sci. 21:165-180; 1977.

33. Cabasso, I.; Klein, E.; Smith, J. K. Polysulfone hollow fibers. 1. Spinning and properties. J. Appl. Polym. Sci. 20:2377-2394; 1976.

34. Lafreniére, L. Y.; Talbot, F. D. F.; Matsuura, T.; Sourirajan, S. Effect of polyvinylpyrrolidone additive on the performance of polyethersulfone ultrafiltration membranes. Ind. Eng. Chem. Res. 26:2385-2389; 1987.

35. Reuvers, A.J. Membrane formation. Diffusion induced demixing processes in ternary polymeric systems. Enschede, The Netherlands: University of Twente; 1987. Dissertation.

36. O'Leary, W. Practical handbook of microbiology. Boca Raton, FL: CRC Press; 1988.

Received August 1, 1991

Accepted May 8, 1992 